\title{
ФЕНОМЕНОЛОГИЯ КАК ОСНОВА ПСИХОЛОГО-ПЕДАГОГИЧЕСКОГО СОПРОВОЖДЕНИЯ ПЕРЕЖИВАНИЯ ПЕДАГОГАМИ ПРОФЕССИОНАЛЬНОГО КРИЗИСА ЛИЧНОСТИ
}

\section{Садовникова Н.О.}

Цель. В статье анализируются возможности применения феноменологии как исследовательского метода и как основы проектирования программ психолого-педагогического сопровождения переживания педагогами профессионального кризиса личности.

Метод и методология проведения работы. В качестве основной методологии выступает феноменология. Также в качестве методологической основы исследования выступают работы отечественных и зарубежных исследователей, в которых раскрываются содержание категорий «кризис» и «пережсивание». Основным методом исследования явилось полуструктурированное интервью, разработанное на основе феноменологического подхода.

Результаты. На основании результатов теоретико-эмпирического исследования дается определение категорий «профессиональный кризис личности», раскрывается содержание прочесса переживания кризиса. Применение феноменологического подхода как основы для проектирования содержания интервью, направленного на раскрытие содержания прочесса переживания педагогами профессионального кризиса личности, позволило обосновать возможности применения феноменологии как исследовательского метода. А анализ работ авторов, раскрывающих возможности феноменологии как психотерапевтического метода, позволил обозначить основные направления применения феноменологии как основы проектирования психолого-педагогического сопровождения педагогов, переживающих профессиональный кризис личности. 
Область применения результатов. Полученные результаты могут быть использованы в работе психологической службы образовательных организаций, при проектировании программ сопровождения профессионального развития и профессиональной деятельности педагогов.

Ключевые слова: профессиональный кризис личности; переживание; феноменология; феноменологический метод; психологопедагогическое сопровождение

\section{PHENOMENOLOGY AS THE BASIS \\ OF PSYCHOLOGICAL AND PEDAGOGICAL SUPPORT OF EXPERIENCE OF PROFESSIONAL CRISIS OF PERSONALITY BY TEACHERS}

\section{Sadovnikova N.O.}

Purpose. In the article the possibilities of using phenomenology as a research method are analyzed. In addition, phenomenology is considered as the basis for designing programs for psychological and pedagogical support for the experience of teachers of a professional personality crisis.

Method and methodology. The main methodology is phenomenology. Also, as the methodological basis of the study is the work of domestic and foreign researchers, which revealed the contents of the categories of "crisis" and "experience". The main research method was a semi-structured interview, developed on the basis of a phenomenological approach.

Results. The content of the process of experiencing the crisis is disclosed, a definition is given of the categories "professional personality crisis" on the basis of the results of a theoretical and empirical study. The application of the phenomenological approach as the basis for designing the content of the interview. The interview is aimed at revealing the content of the process experienced by teachers of a professional personality crisis. This allowed us to substantiate the possibilities of applying phenomenology as a research method. And the analysis of the works of the authors, revealing the possibilities of phenomenology as 
a psychotherapeutic method, made it possible to identify the main directions of the application of phenomenology as the basis for designing psychological and pedagogical support for teachers experiencing a professional personality crisis.

Practical implications. The results can be used in the educational psychological service organizations in the design of programs support professional development and professional work of teachers.

Keywords: professional personality crisis; experience; phenomenology; phenomenological method; psychological and pedagogical support.

\section{Введение}

В Концепции модернизации Российского образования в качестве одной из главных задач российской образовательной политики обозначено - обеспечение современного качества образования при сохранении фундаментальности и его развитие в соответствии с актуальными и перспективными потребностям личности, общества и государства. Одним из путей решения этой задачи является обеспечение психологической безопасности образовательного процесса, в том числе за счет повышения уровня психологического благополучия педагогов.

В тоже время, на фоне перманентных реформ в системе образования, в условиях возрастающих требований к личности со стороны государства и общества, усиливаются процессы дезадаптации педагога, как отражения личностных противоречий, связанных с разрывом между уровнем предъявляемых требований и наличием внутренних энергоресурсов, усиливается внутриличностное напряжение, у педагога возникает ощущение бесцельности собственной работы. Все это приводит к возникновению состояния профессионального кризиса личности.

\section{Категория «кризис» в зарубежной и отечественной психологии}

Впервые к кризисной проблематике в контексте травмирующей ситуации обратился E. Lindemann [10]. В дальнейшем, в работах других исследователей (G. Caplan, S.-H. Fillip, D. Ulich и др.) под 
кризисом понимается период неравновесия, ограниченный по времени, как неожиданное событие или переживание, которое личность не может «переработать» и который не может быть преодолен посредством имеющихся у личности ресурсов.

В отечественной психологии основы изучения (возрастных кризисов) кризисов, их психологического смысла и механизмов было заложено Л.С. Выготским [3, с. 124]. В контексте жизненного и личностного становления, кризис трактуется как феномен внутреннего мира человека, который проявляется в различных формах переживания непродуктивности своей жизни (Р.А. Ахмеров), как неизбежный переход от одной возрастной стадии к следующей (Е.Л. Солдатова), как качественный переходом человека на новый этап, в котором открывается новая картина мира (Т.Д. Марцинковская).

На существование кризисов профессионального развития (становление) указывают Л.И. Анцыферова, Э.Ф. Зеер, Е.А. Климов, А.К. Маркова, Л.М. Митина, Н.С. Пряжников, Э.Э. Сыманюк, А.Р. Фонарев и др.

В контексте нашего исследования интересен подход Ф.Е. Василюка, в котором под кризисом понимает критический момент и поворотный пункт на жизненном пути, сопровождающийся внутренним нарушением эмоционального баланса, наступающим под влиянием угрозы, создаваемой внешними обстоятельствами [2]. Автор отмечает, что в ситуации кризиса возникает разлад между сознанием и бытием, происходит утрата смысла, преодоление которой возможно за счет перестройки системы ценностей и смыслов [2, с. 29].

Также интерес представляет подход А.О. Прохорова, который относит кризис к неравновесным ситуациям, которые в обычной жизни могут быть вызваны разрывом привычной системы отношений, утратой значимых ценностей, невозможностью достижения поставленных целей, потерей близкого человека и т.д. [5] Все это сопровождается отрицательными эмоциональными переживаниями, неспособностью реально оценить ситуацию и найти рациональный выход из нее [5, с. 222]. 
На основании анализа работ обозначенных выше авторов, можно констатировать, что феноменология кризиса раскрывается через такие категории, как «переживание», «утрата смысла», «конфликт ценностей», «дезадаптация», «трансформация жизненного плана», «снижение осмысленности жизни» и пр.

В свете этого, под профессиональным кризисом личности педагога мы понимаем длительное неравновесное состояние субъекта труда, вызванное рассогласованием ценностно-смысловой сферы личности и актуализирующее процесс переживания [7] . Возникновение профессионального кризиса личности характеризуется появлением у человека неуверенности в своих силах, несогласием с самим собой, осознанием необходимости переоценки себя, появлением неясности жизненных целей, непониманием как жить дальше, потерей чувства нового, отставанием от жизни и т. д. [6].

Поскольку профессиональный кризис личности затрагивает пласт сознания личности и приводит к его трансформации (по аналогии с личностным кризисом), поэтому при изучении вопроса о том, каким образом личность разрешает профессиональный кризис, целесообразно оперировать категорией «переживание». Именно категория переживания позволяет исследователю раскрыть содержание той внутренней деятельности, которая разворачивается в сознании человека, попавшего в ситуацию профессионального кризиса; деятельности, позволяющей устранить разногласие между бытием и сознанием.

Переживание представляет собой внутреннюю работу по восстановлению душевного равновесия и устранению рассогласования между сознанием и бытием и характеризует уникальность внутреннего мира личности, ее сознания и всей жизни в целом.

В отечественной психологии к категории переживания, как базовой, первичной характеристике сознания, впервые обратился Л.С. Выготский [3]. По его мнению, переживание являются единицей анализа при изучении взаимодействия личности и среды. Автор рассматривает переживание как деятельность по перестройке психологического мира, направленную на установление смыслового соответствия между сознанием и бытием [3]. 
По мнению Ф.Е. Василюка, сущность переживания заключается в следующем: когда человек переживает постигшую его утрату, главным является вопрос о том, как ему удастся преодолеть страдание, выдержать испытание, выйти из кризиса и восстановить душевное равновесие, психологически справиться с ситуацией [2]. Речь идет о некотором активном, результативном внутреннем процессе, реально преобразующем психологическую ситуацию, о переживании-деятельности», целью которой является добывание осмысленности дальнейшей жизни [2] .

Поскольку профессиональный кризис - это ситуация, когда личность не в состоянии реализовать задуманное в профессии, ситуация, в которой возникает невозможность жить, реализовывать внутренние необходимости своей жизни, ситуация, когда перед личностью ставится «задача на смысл», требующая своего разрешения [6]. Именно категория переживания позволяет исследователю раскрыть содержание той, внутренней деятельности, которая разворачивается в сознании педагога. В свете этого применение для исследования содержания переживания традиционного психологического измерения невозможно. Для исследования содержания переживания педагогами профессионального кризиса целесообразно обратиться к стратегиям качественного исследования, одной из которых является феноменологический подход.

\section{Феноменология как метод исследования содержания переживания педагогами профессионального кризиса личности}

Феноменологический подход сегодня приобретает особую актуальность в исследовании структуры некоторого переживания, смыслов и отношения человека к чему-либо [9]. Он предполагает реализацию методологии «от первого лица», которая постулирует идею о нередуцируемости переживания. Ее предметом являются живое переживание, субъективный опыт, данные сознания, феномены и феноменальные данные [15].

Феноменологический метод - это специальный метод описания и анализа собственных переживаний, опирающийся на рефлексию 
и принципы очевидности и беспредпосылочности [9]. Испытуемым в феноменологическом исследовании может стать любой человек, имеющий соответствующее переживание или опыт и способный хотя бы минимально его описать [9].

В цикле исследований [13], проведенных ранее, мы обосновании возможности применения феноменологического метода для исследования содержания процесса переживания педагогами профессионального кризиса личности. Для этого нами было разработано полуструктурированное феноменологическое интервью, вопросы которого охватывали несколько аспектов процесса переживания педагогами профессионального кризиса личности: от общего мироощущения и переживаний до кризиса, до описания деятельности по преодолению кризиса.

Всего в исследовании приняли участие 150 педагогов общеобразовательных организаций, средний стаж работы которых 8,6 лет. Все испытуемые - женщины, средний возраст 28,4 года. Поскольку в контексте нашего исследований особый интерес представляли педагоги, имеющие опыт переживания профессионального кризиса (это одно из важнейших условий применения феноменологической исследовательской стратегии). Поэтому из общей выборки мы отобрали 70 педагогов, которые такой опыт имели.

Анализ ответов педагогов позволил установить, что основной аспект переживания связан с изменением смыслового контекста работы (21\% ответов от общего количества высказываний). Многие педагоги отмечали: «мне казалось, что все забывается», «тетради на проверку домой перестала брать», «мне не удается понять нужно ли мне это», «стала меньше реагировать на требования родителей», «теперь силой воли заставляю себя идти, профессиональные обязанности выполняю по привычке, автоматически», «смысл стал - уберечь своего ребенка от того, что сейчас в детских садах..», «очень разочаровала система образования», «я стала по-другому смотреть на свою деятельность» и др.

Для многих педагогов переживание профессионального кризиса сопровождается рефлексией содержания профессиональной 
деятельности (18\% ответов от общего количества высказываний), затем актуализируется рефлексия внутреннего мира (13\% ответов от общего количества высказываний) и социального окружения (13\% ответов от общего количества высказываний).

Полученные результаты подтвердили наше предположение о том, что феноменологический метод может быть использован для изучения содержания переживания педагогами профессионального кризиса личности.

Вместе с тем феноменология может выступить и как основа проектирования программ психолого-педагогического сопровождения переживания педагогами профессионального кризиса личности

\section{Феноменология как основа}

\section{психолого-педагогического сопровождения}

Как отмечает А.М. Улановский, основная задача феноменологии заключалась в интуитивном, непредубежденном, доскональном, дескриптивном, аналитическом установлении различий и приведении к ясности феноменов сознательной жизни и переживания [9]. Именно с опорой на феноменологию был разработан оригинальный психотерапевтический подход Ю. Джендлина, который заключается в особой форме концентрации, самопогружении и максимально проницательной артикуляции собственных переживаний [4]. В процессе применения метода фокусирования психотерапевт обращает человека к ощущаемому смыслу волнующего событии и помогает ему найти наиболее подходящий образ, слово или выражение, что обычно приводит к чувству облегчения у клиента. Феноменология должна помочь психиатру понять, вжиться, всмотреться в структуру и способы бытия-в-мире больного человека, представленные в его мировидении [1].

Поскольку важным предиктором продуктивного профессионального развития является осознание смысла и значимости своей деятельности, самоопределение в ней, то утрата смысла неизбежно приводит к ситуации профессионального кризиса. Как уже отмечалось выше профессиональный кризис личности это длительное 
неравновесное состояние субъекта труда, вызванное рассогласованием ценностно-смысловой сферы личности и актуализирующее процесс переживания. Переживание, в свою очередь, представляет собой внутреннюю работу по восстановлению душевного равновесия и устранению рассогласования между сознанием и бытием и характеризует уникальность внутреннего мира личности, ее сознания и всей жизни в целом. Соответственно, успешное сопровождение профессионального развития личности возможно, если психолог имеет представление о том внутреннем образе профессиональной реальности, который есть у профессионала. Принятие этого внутреннего мира, признание его уникальности и очевидности и проектирование на этой основе помогающей деятельности возможно в случае использования феноменологии.

Феноменология выступает одним из методологических подходов к проектированию и реализации программы психолого-педагогического сопровождения переживания педагогами профессионального кризиса личности. Цель психолого-педагогического сопровождения переживания профессионального кризиса личности - актуализация профессионально-психологического потенциала субъекта деятельности для конструктивного разрешения профессионального кризиса личности. В свете этого обозначим основные векторы реализации феноменологического подхода в психолого-педагогическом сопровождении переживания педагогами профессионального кризиса личности:

1. Поскольку переживание это центральный феномен профессионального кризиса личности, то для работы с переживанием важна его вербализация, описание его в конкретных категориях. Феноменологический подход (как уже отмечалось выше) предполагает описание респондентом (в нашем случае педагогом) своих переживаний в конкретных словах, фразах, метафорах.

2. Последовательное прояснение, раскрытие и чуткое описание переживание - суть феноменологии. При этом основная задача феноменологии - «запуск» процесса изменения переживания. В процессе психолого-педагогического сопровождения педагог концентрирует свое внимание на процессе переживания профессионального кри- 
зиса личности, на то, что он чувствует, каким видит смысл своей профессиональной деятельности. В процессе этой внешней и внутренней работы происходит поиск ресурсов для преодоления профессионального кризиса личности.

3. В ходе описания содержания переживания «запускаются» процессы рефлексии (проведенное феноменологическое исследования подтверждает это), которые обеспечивают прояснение всей ситуации профессионального развития, нахождение новой профессиональной перспективы, поиск ресурсов для прохождения ситуации кризиса.

Таким образом, в контексте реализации процесса сопровождения переживания педагогами профессионального кризиса личности, феноменологии обладает хорошим исследовательским и помогающим ресурсом. Посредством феноменологического анализа возможно не только прояснить сами переживания педагога, но и актуализировать процессы рефлексии и поиска ресурсов для разрешения кризиса.

\section{Заключение}

Итак, на основании теоретико-эмпирического исследования мы можем сформулировать следующие выводы:

1. Категория «кризис» и «переживание» представляет интерес, как для зарубежных, так и для отечественных психологов. При этом именно в отечественной психологии исследователи обращаются к изучению кризисов в контексте профессионализации личности. Вместе с тем, исследований категорий «профессиональный кризис личности» и «переживание профессионального кризиса личности» в настоящее время нет. Под профессиональным кризисом личности мы понимаем - длительное неравновесное состояние субъекта труда, вызванное рассогласованием ценностно-смысловой сферы личности и актуализирующее процесс переживания, которое в свою очередь нацелено на устранение этого рассогласования.

2. На основании работ, раскрывающих сущность феноменологии, мы предположили, что для исследования содержания переживания педагогами профессионального кризиса личности целесообразно использовать феноменологический метод. Анализ ответов педаго- 
гов на вопросы полуструктурированного феноменологического интервью подтвердили данное предположение и позволили описать содержание переживания.

3. Поскольку феноменология получила свое широкое распространение и как психотерапевтический метод в работе с переживаниями, мы предложили рассматривать феноменологию и как основу психолого-педагогического сопровождения переживания педагогами профессионального кризиса личности. Это позволит не только раскрыть содержание переживания, но и актуализировать в сознании педагогов процессы рефлексии собственных ресурсов, процессы смыслообразования.

Полученные результаты и выводы не носят законченного характера. исследование будет продолжено в направлении реализации программы психолого-педагогического сопровождения переживания педагогами профессионального кризиса личности и оценке ее эффективности.

\section{Информация о конфликте интересов.}

Авторы заявляют об отсутствии конфликта интересов.

\section{Информация о спонсорстве.}

Исследование выполнено при поддержке РФФИ (Отделение гуманитарных и общественных наук), в рамках научно-исследовательского проекта «Психологические механизмы переживания педагогами профессионального кризиса личности», проект № 1636-01031.

\section{Список литературы}

1. Бинсвангер Л. Феноменология и психопатология // Логос. 1992. №3. C. $125-136$.

2. Василюк Ф.Е. Психология переживания (анализ преодоления критических ситуаций). Москва: МГУ, 1984. 200 с.

3. Выготский Л.С. Биогенетический подход в психологии и педагогике // Хрестоматия по возрастной психологии / Под ред О.А. Карабановой, А.И. Подольского, Г.В.Бурменской. М.: МГУ 1999. 315 с. 
4. Джендлин Ю. Фокусирование. Новый психотерапевтический метод работы с переживаниями. М.: Класс, 2000. 293 с.

5. Прохоров А.О. Теоретические и методологические аспекты проблемы неравновесных психических состояний // Прохоров А.О. (ред.). Психология состояний. Москва: ПЕР СЭ; Санкт-Петербург: Речь, 2004. $608 \mathrm{c}$.

6. Садовникова Н.О. Переживание как деятельность по разрешению профессионального кризиса личности // Фундаментальные исследования. 2015. № 2-6. С. 1328-1332; URL: https://fundamental-research. $\mathrm{ru} / \mathrm{ru} / \mathrm{article} / \mathrm{view}$ ?id=37030 (дата обращения: 01.02.2018).

7. Садовникова Н. О., Сергеева Т.Б. Смысложизненные ориентации педагогов в ситуации профессионального кризиса личности // Научный диалог. 2016. № 9 (57). С. 297-310.

8. Садовникова Н.О. Ценностно-смысловые особенности ненормативного кризиса профессиональной карьеры // Образование и наука. 2009. № 6 (2). С. 89-97.

9. Улановский А.М. Феноменологическая психология: качественные исследования и работа с переживанием. Москва: Смысл, 2012. 255 с.

10. Caplan, G. Principles of preventive psychiatry. New York, London: Basis Books. 1964. 304 p.

11. Fillip S.-H. \& Aymanns P. Kritische Lebensereignisse und Lebenskrisen. Vom Umgang mit den Schattenseiten des Lebens. Stuttgart: Kohlhammer. 2010. 448 p.

12. Lindemann E. Symptomatology and management of acute grief // American Journal of Psychiatry. 101 (1944), 141-148. Режим доступа: http:// www.nyu.edu/classes/gmoran/LINDEMANN.pdf. (дата обращения 13.07.2016).

13. Sadovnikova N.O., Sergeeva T.B., Suraeva M.O., Kuzmina O.Y. Phenomenological Analysis of Professional Identity Crisis Experience by Teachers // International Journal of Environmental and Science Education. 2016. № 11 (14), pp. 6898-6912.

14. Ulich D., Hausser K., Mayring Ph., Strehmel P., Kandler M., Degenhardt B. Psychologie der Krisenbewaeltigung eine Laengsschnittuntersuchung mit arbeitslosen Lehrern. Weinheim: Beltz, 1985. 244 p. 
15. Varela F.J., Shear J. First-person accounts: why, what, and how. The view from within: First-person approaches to the study of consciousness // Journal of Consciousness Studies, 6, No. 2-3, 1999, pp. 1-14. Режим доступа: http://www.imprint.co.uk/pdf/VFW_introduc.pdf(дата обращения 13.07.2016).

\section{References}

1. Binsvanger L. Logos. 1992. №3, pp. 125-136.

2. Vasilyuk F.E. Psikhologiya perezhivaniya (analiz preodoleniya kriticheskikh situatsiy) [Psychology of experience (analysis of the overcoming of critical situations)]. Moscow: MGU, 1984. 200 p.

3. Vygotskiy L.S. Khrestomatiya po vozrastnoy psikhologii [Reader on the basis of age psychology]. Ed O.A. Karabanova, A.I. Podol'sky, G.V. Burmenskaya. M.: MGU 1999. 315 s.

4. Dzhendlin Yu. Fokusirovanie. Novyy psikhoterapevticheskiy metod raboty $s$ perezhivaniyami [Focusing. A new psychotherapeutic method of working with experiences]. M.: Klass, 2000. 293 p.

5. Prokhorov A.O. (ed.). Psikhologiya sostoyaniy [Psychology of states]. Moscow: PER SE; St. Petersburg: Rech', 2004. 608 p.

6. Sadovnikova N.O. Fundamental'nye issledovaniya. 2015. № 2-6, pp. 1328-1332; https://fundamental-research.ru/ru/article/view?id=37030

7. Sadovnikova N. O., Sergeeva T.B. Nauchnyy dialog. 2016. № 9 (57), pp. 297-310.

8. Sadovnikova N.O. Obrazovanie i nauka. 2009. № 6 (2), pp. 89-97.

9. Ulanovskiy A.M. Fenomenologicheskaya psikhologiya: kachestvennye issledovaniya i rabota s perezhivaniem [Phenomenological psychology: qualitative research and work with experience]. Moscow: Smysl, 2012. 255 p.

10. Caplan G. Principles of preventive psychiatry. New York, London: Basis Books. 1964. 304 p.

11. Fillip S.-H. \& Aymanns P. Kritische Lebensereignisse und Lebenskris-en. Vom Umgang mit den Schattenseiten des Lebens. Stuttgart: Kohlhammer. 2010. 448 p.

12. Lindemann E. Symptomatology and management of acute grief. American Journal of Psychiatry. 101 (1944), 141-148. Rezhim dostupa: http:// 
www.nyu.edu/classes/gmoran/LINDEMANN.pdf. (data obrashcheniya 13.07.2016).

13. Sadovnikova N.O., Sergeeva T.B., Suraeva M.O., Kuzmina O.Y. Phe-nomenological Analysis of Professional Identity Crisis Experience by Teachers. International Journal of Environmental and Science Education. 2016. № 11 (14), pp. 6898-6912.

14. Ulich D., Hausser K., Mayring Ph., Strehmel P., Kandler M., Degenhardt B. Psychologie der Krisenbewaeltigung eine Laengsschnittuntersuchung mit arbeitslosen Lehrern. Weinheim: Beltz, 1985. 244 p.

15. Varela F. J., Shear J. First-person accounts: why, what, and how. The view from within: First-person approaches to the study of consciousness. Journal of Consciousness Studies, 6, No. 2-3, 1999, pp. 1-14. http:// www.imprint.co.uk/pdf/VFW_introduc.pdf

\section{ДАННЫЕ ОБ АВТОРЕ}

Садовникова Надежда Олеговна, заведующая кафедрой профессиональной педагогики и психологии, кандидат психологических наук, доцент

ФГАОУ ВО «Российский государственный профессиональнопедагогический университет»

ул. Машиностроителей, 11, г. Екатеринбург, 620012, Российская Федерачия nosadovnikova@gmail.com

\section{DATA ABOUT THE AUTHOR}

Sadovnikova Nadezhda Olegovna, Head of Department, Department of Professional pedagogy and Psychology, $\mathrm{PhD}$ in Psychology, Associate Professor

Russian State Vocational Pedagogical University

11, Mashinostroitelej Str., Yekaterinburg, 620012, Russian Federation

nosadovnikova@gmail.com

ORCID: 0000-0001-8738-3996

Scopus Author ID: 57191169642 